\title{
BADUR HOGAR, UNA APUESTA COSMOPOLITA PARA EL CINE REGIONAL
}

\author{
Badur Hogar, a cosmopolitan bet for regional cinema
}

\author{
Iván Morales* \\ https://orcid.org/0000-0002-0802-8484
}

\section{Resumen}

En este artículo analizaré Badur Hogar (2019) de Rodrigo Moscoso, una película salteña que se apropia del género global de la comedia romántica para narrar una historia local y, a su vez, universal. La película le escapa al slogan turístico -"Salta, la linda"- pero no renuncia a construir, desde la capital de la provincia, un cine de aspiraciones urbanas que invita a preguntarse si el llamado "cine regional" puede ser también cosmopolita sin quedar atrapado en la salteñidad for export y sin tener que recurrir a cierto estilo codificado del cine independiente que demandan los festivales. Moscoso no evade aquello que sería propio de una cultura o identidad local, es decir, un modo situado de ser, actuar y hablar; pero se sirve de los recursos de la comedia para hacer risible todo intento de convertir a la imagen -cinematográfica- de la salteñidad en una identidad fija condenada a repetir eternamente las mismas prácticas, tradiciones, paisajes, tópicos y personajes.

$$
<\text { Cine salteño }><\text { Comedia romántica }><\text { Cine regional }>
$$

\begin{abstract}
In this article I will analyze Rodrigo Moscoso's Badur Hogar (2019), a film from Salta that appropriates the romantic comedy genre to narrate a local and, at the same time, universal story. The film avoids the touristic slogan - "Salta, la linda"- but does not give up the chance to create, right from the capital city of Salta, a cinema of urban aspirations. This raises the questions of whether the so-called "regional cinema" can be cosmopolitan without falling into exotism for export, or whether it has to adjust itself to a certain independent film codified style that film festivals demand. Moscoso does not reject the typical elements of local culture or identity: a certain mode of being, acting, and talking. But he uses the comedy resources to mock any intention of converting the salteñidad into a fixed identity condemned to repeat the same practices, traditions, landscapes, topics, and characters.
\end{abstract}

$<$ Cinema of Salta $><$ Romantic comedy $><$ Regional cinema $>$

Recibido: 28/09/2020//Aceptado: 30/11/2020

\footnotetext{
* Consejo Nacional de Investigaciones Científicas y Técnicas (CONICET) - Instituto de Historia del Arte Argentino y Latinoamericano, Facultad de Filosofía y Letras, Universidad de Buenos Aires (UBA), Argentina, ivanmorales@gmail.com
} 


\section{Introducción}

Existe un lugar común y extendido, en torno a las producciones estéticas de las provincias, que dice que estas deben representar paisajes y tópicos presuntamente inherentes a su cultura regional. Cuando se cumple esta exigencia o expectativa, muchas veces proveniente del exterior (es decir, Buenos Aires, centro político y económico del país) pero también motivada por las políticas culturales promovidas desde el interior de cada provincia, el resultado suele consistir en producciones donde "lo típico" (o incluso "lo pintoresco" y "el color local") obturan la posibilidad de figuraciones heterogéneas. En el caso de Salta, es una demanda con una potencia particular, ya que aquellos rasgos más exaltados en las representaciones dominantes de la provincia y su cultura -la belleza natural, el pasado indígena y colonial, el tradicionalismo, la religiosidad católica, el folclore y la figura del gaucho norteño heredero de Güemes- no solo crean una imagen homogénea, sin fisuras, heroica, bella y amable ("Salta, la linda"). Contribuyen, también, a que Salta perviva en el imaginario nacional como una suerte de reservorio de una argentinidad esencial hoy perdida y de un tiempo fundacional. Esta concepción se remonta a principios del siglo veinte ${ }^{1}$ y refuerza un imaginario, aún vigente, en torno a la Buenos Aires moderna, cosmopolita y desarraigada frente al noroeste tradicional y originario. En un doble movimiento que, siguiendo a Arancibia y a Barrios (2018, p. 54), tiende a la hiperrepresentación de la región (exotismo y pintoresquismo) o a la subrrepresentación (atraso y deformación del ideal de nación).

Como estudió Arancibia (2015), ${ }^{2}$ esta imagen estática, atemporal y sin conflictos socio-étnicos, ha encontrado un discurso alternativo y especialmente incisivo en el inédito cine salteño que se desarrolló en las últimas décadas. Por diversas razones, y con intereses, estrategias y poéticas cinematografías muy distintas, hay dos nombres ineludibles y sumamente influyentes en los comienzos de este proceso: Alejandro Arroz y Lucrecia Martel. El primero, menos conocido a escala nacional e internacional, no solo es uno de los pioneros de la acotada producción audiovisual del noroeste argentino, sino también fue un agente fundamental en el desarrollo del campo local. ${ }^{3}$ Martel, no hace falta decirlo, es ya una de las figuras más importantes de la historia del cine argentino

\footnotetext{
Alrededor del Primer Centenario de Mayo, el nacionalismo cultural reaccionó al proceso modernizador y al aluvión migratorio de Buenos Aires buscando nuevos fundamentos - con una perspectiva esencialista, por fuera de la metrópoli y en un tiempo histórico pasado- para la construcción de una identidad nacional que amalgamara a la nueva sociedad (Devoto, 2002). Si bien intelectuales como Ricardo Rojas, Manuel Gálvez y Leopoldo Lugones privilegiaron el paisaje de la llanura pampeana al pensar la literatura nacional, para el caso de las artes plásticas Fasce (2017) ha demostrado que la mirada se dirigió hacia el noroeste argentino, el cual aglutinaba "un paisaje complejo en términos visuales, un conjunto de tipos humanos alrededor de los que se podía reconfigurar la definición del "nativo" o el "criollo" y un pasado estratificado en múltiples capas (precolombino, colonial, hispanoamericano)" ( p. 25).

2 La producción crítica de Arancibia sobre el cine y el audiovisual salteño es muy amplia y está diseminada en distintas publicaciones. Su tesis doctoral (2015) reúne gran parte de ellas.

3 Arroz dios sus pasos iniciales como asistente de dirección del jujeño Miguel Pereira en La deuda interna (1988), en los noventa fundó PALCA (Producciones Alternativas de Cine y Televisión) y en el 2007 realizó su primer largometraje de ficción, Luz de invierno. Su cine se caracteriza por la representación de sectores subalternos. Como gestor creo la Semana de Cine Argentino en Salta y el Taller Anual de Cine en Salta, destinado a formar profesionales en la región del NOA.
} 
y del cine contemporáneo internacional. Con sus tres primeras películas instauró una nueva forma de ver y escuchar, experimentando con todas las posibilidades de la puesta en escena para narrar, observar y descubrir las complejidades de la sociedad salteña desde un realismo minucioso que no teme saltar al fantástico.

Pero ¿existe la posibilidad de otro tipo de respuesta a aquella construcción cristalizada y chata que dispute el sentido reinventando la Salta turística y pintoresca sin fugarse hacia los márgenes, como Arroz, o mediante una estética decididamente disruptiva, como Martel? En este artículo, analizaré Badur Hogar (2019) de Rodrigo Moscoso, una película que se apropia de la comedia romántica — género global y de fórmulas narrativas industriales y populares - para narrar una historia urbana salteña. Moscoso le escapa al slogan turístico, pero no renuncia a construir, desde Salta capital, un cine de aspiraciones urbanas que obliga a preguntarse si el llamado "cine regional" puede ser también cosmopolita; sin quedar atrapado en la salteñidad for export y sin tener que recurrir a cierto estilo codificado del cine independiente o del "cine arte" que demandan los festivales. Moscoso no evade aquello que sería propio de una cultura o identidad local/regional, es decir, un modo situado de ser, actuar y hablar. Pero se sirve de los recursos de la comedia para hacer risible todo intento de convertir a la imagen (cinematográfica) de la salteñidad en una identidad fija condenada a repetir eternamente las mismas prácticas, tradiciones, paisajes, tópicos y personajes. La película se propone una suerte de cosmopolitismo estratégico y regional, donde los localismos se reinventan a partir de formas globales. ${ }^{4}$

\section{Un antecedente olvidado a la sombra de Martel}

Aunque Badur Hogar es apenas su segunda película, lo cierto es que Moscoso está lejos de ser una joven promesa. Sus comienzos se remontan al 2001, cuando estrenó Modelo 73 en el BAFICI, una aparición que causó cierto entusiasmo en el contexto de lo que más tarde se denominó Nuevo Cine Argentino. Aquella película era también una historia urbana filmada en la ciudad de Salta, pero su relación con la comedia estaba atravesada por el enrarecimiento de las fórmulas genéricas, dejando ver una clara influencia del cine de Martín Rejtman, tanto en el tono como en la manera de narrar. Pese a este promisorio debut, el tiempo la fue dejando en el olvido y hoy es raro encontrarla entre los títulos más representativos del NCA, cuando se revisa ese período intenso y decisivo que reconfiguró la cinematografía nacional. Tal vez una razón para explicar esto pueda encontrarse en cierto devenir maldito de la película, no solo porque Moscoso se alejó del centro de la escena cinematográfica sino porque Modelo 73 nunca se estrenó comercialmente, y recién volvió a proyectarse en el 2005 cuando los debates y las expectativas en torno al NCA eran otros.

\footnotetext{
${ }^{4}$ Contra las connotaciones habituales que se le asignan al cosmopolitismo (elitista, desarraigado, intelectual, metropolitano), aquí pienso al cosmopolitismo estético, siguiendo a Aguilar (2009, p. 10), como "una instancia móvil, operativa y disponible que se propone, en un mismo gesto (el de la actividad artística) redefinir las nociones de lo local, lo nacional y lo universal".
} 
Esta existencia fugaz y a destiempo, que seguramente contribuyó a que se la marginara, a su vez la condenó a cierta irrelevancia en su dimensión regional, aun cuando al momento de su aparición la cantidad de películas hechas en Salta era mínima. Tapada también por el impacto y la omnipresencia de La ciénaga, que se estrenó pocos meses después (así como por las dos películas siguiente de Martel que completaron una suerte de trilogía de historias localizadas en la provincia), no suele considerársela en la filmografía del cine salteño. ${ }^{5}$ Es cierto que Moscoso estudió en la Universidad del Cine, pero lo mismo aplica a Martel que lo hizo en la Escuela Nacional de Experimentación y Realización Cinematográfica, es decir, ambos son salteños formados en Buenos Aires que regresaron a su provincia a filmar. Incluso podría decirse que La ciénaga es decididamente más porteña, si se piensa en sus productores y en su elenco, frente a la pequeña escala de producción de Modelo 73 y en el uso de actores locales. Con todo, Martel y su cine están inevitablemente identificados con Salta y con una nueva mirada sobre ella. No deja de ser llamativo, más allá de los méritos de cada ópera prima y el grado de ruptura con la historia cinematográfica precedente, el destino crítico e historiográfico de ambas. Es como si la película de Martel, al tratar temas nodales de la sociedad salteña y su decadencia, mereciera un lugar que la película de Moscoso (sobre el fin de la adolescencia de un grupo de amigos que compran un Chevy usado e intentan enamorar a unas chicas) nunca podría ocupar; porque al fin y al cabo es una historia inocente que, si se le quitan algunos localismos, pudo haber sido filmada en Buenos Aires.

Un año antes de su estreno en el BAFICI, Modelo 73 se exhibió en el Festival de Cine Latinoamericano de Toulouse, en una versión sin terminar. Silvia Schwarzböck, en El Amante, escribió sobre ella a contrapelo de lo que sucedería tiempo después. La película de Moscoso, dice Schwarzböck, es "muy diferente de la media del cine latinoamericano" y, además, "es una película urbana, con personajes urbanos, pero de una capital de provincia. Este dato enrarece todo, porque el spleen salteño no tiene paralelismo con el de Buenos Aires, ni tampoco se parece al spleen suburbano de los films de Raúl Perrone. Este descentramiento geográfico que afecta a los personajes es una novedad, que después habrá que ver si admite alguna comparación con La ciénaga, la película de Lucrecia Martel [la cual todavía no se había estrenado al momento de escribir la nota]" (2000, p. 44).

Claro que el descentramiento geográfico provocado por el trabajo visual y sonoro de Martel, con la yunga pantanosa que rodea a la familia decadente de La ciénaga, tuvo una potencia sin igual. Implicó un uso del paisaje totalmente disruptivo para el cine argentino y distorsionó la imagen tradicional de la naturaleza salteña en una belleza tétrica ${ }^{6}$. Pero Modelo 73, más pequeña e inscripta en otro régimen visual y narrativo, sigue siendo una novedad como pensó tempranamente Schwarzböck. Moscoso registra

\footnotetext{
${ }_{5}^{5}$ En los principales estudios sobre el Nuevo Cine Argentino producidos desde Buenos Aires no se la menciona. Pero tampoco lo hace Arancibia (2015) en su tesis doctoral dedicada específicamente al cine del NOA del nuevo milenio.

6 Jens Anderman escribió sobre La ciénaga como una ruralidad gótica ya que concibe a "lo no urbano como primitivo y regresivo más que redentor y transparente" $(2015$, p. 135).
} 
la experiencia particular de tres adolescentes durante un verano en la ciudad capital salteña ${ }^{7}$, sin recaer en los recorridos que promueve el turismo donde la única imagen posible pareciera ser la del centro histórico y su pasado colonial. Una tarea en apariencia fácil, pero que no se repitió justamente hasta Badur Hogar, realizada por el mismo director.

De nuevo, como si la urbanidad le estuviese negada al cine regional, no es casual que la generación siguiente de directores del noroeste argentino no solo adoptaran ciertos procedimientos de la poética marteliana sino, también, pusieran en pantalla a familias de la clase media o alta. Con el objeto de indagar en las diversas formas de clasismo, racismo, violencia, religiosidad y sexualidad propias del noroeste que las atraviesan. Este es el caso de las salteñas Nosilatiaj. La belleza (Daniela Seggiaro, 2012), Deshora (Bárbara Sarasola-Day, 2013) y de la tucumana Los dueños (Agustín Toscano y Ezequiel Radusky, 2013). Todas primeras películas que suceden en pueblos chicos o espacios rurales y cuya filiación con el cine de Martel es evidente.

Figura 1. En Modelo 73 hasta el paisaje de los cerros está intervenido por la urbanidad.

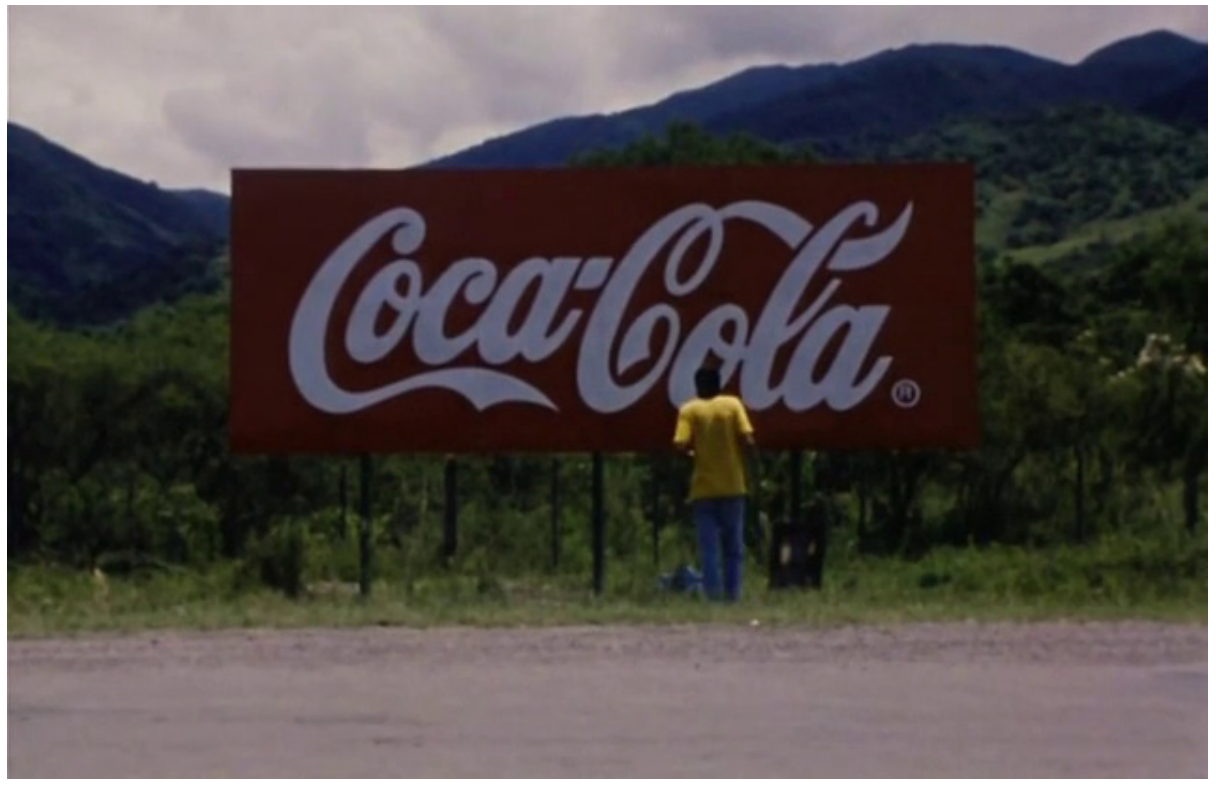

\section{Una comedia un poquito quedada}

Juan Badur limpia piletas. Un dato que no tiene un peso crucial en la historia, ni tampoco está exageradamente subrayado, simplemente es a lo que se dedica el protagonista y funciona como el disparador de algunas situaciones de la trama. Sin embargo, se hace difícil no leerlo como un gesto pícaro (voluntario o involuntario)

\footnotetext{
7 Juan Villegas, coguionista, "tuvo que interiorizarse en lo que para mí ya era familiar" (Schwarzböck, 2000, p. 45).
} 
vinculado a una de las imágenes más potentes y pregnantes del cine argentino contemporáneo: el agua estancada en la pileta de la finca La Mandrágora de La ciénaga. "Hace años que no funciona la bomba para limpiarla, porque en esta casa no funciona nada" decía el personaje de Graciela Borges, y así resumía el estado de podredumbre y descomposición de una familia que, alguna vez, pudo haber tenido cierta posición social pero que ahora no es más que un cuerpo decadente y estancado. ${ }^{8}$ Además, y por extensión, una metáfora visual muy eficaz para describir a la sociedad salteña tradicional, protagonista de las películas de Martel y de sus sucesores. El acto de limpiar piletas de Badur Hogar, entonces, podría ser leído como una invitación a agitar las aguas: hablar de otros temas e incursionar en otros modos narrativos. Moscoso lo hace a través del universo de la comedia romántica, un género que carga con el estigma de ser liviano, frívolo y pasatista pero que, tal vez por esa misma razón, barre sin culpas las aguas pantanosas de la salteñidad. No se trata de evadir los temas densos (el clasismo y el racismo salteños) ${ }^{9}$ o típicos (las imágenes y los tópicos vinculados al pasado colonial y la belleza natural), sino permitirse ironizar sobre ellos y, a la vez, abrir el cine de la provincia y sobre la provincia a nuevos mundos y narrativas posibles.

Badur Hogar narra el romance entre Juan y Luciana. Ambos tienen más de treinta años y no encuentran el rumbo. Ella viene de atravesar una separación turbia, de la que no se nos brinda mucha información. Él es radicalmente inconstante, abandonó todo lo que empezó a estudiar y no tiene trabajo estable. Su refugio es Badur Hogar ${ }^{10}$, el antiguo negocio familiar, ahora cerrado, a donde paradójicamente pasa las noches para escapar de la casa de sus padres. La elección de la comedia romántica para contar esta historia de amor exige, necesariamente, salir del interior de Salta y dirigirse hacia la capital. Es decir, un ambiente urbano más o menos populoso, donde los encuentros azarosos, las identidades invertidas y los enredos ingeniosos sean posibles. Pero además del desplazamiento espacial, este género -sobre todo en la vertiente de la screwball comedy en la cual la película se inscribe- ${ }^{11}$ demanda un ritmo acelerado que no inocentemente entra en contradicción con cierto modo de ser del salteño, cuyo temperamento asociado a la pasividad y a la lentitud aquí se ramifica en más de un sentido.

En su análisis sobre La ciénaga, los personajes estancados de la película de Martel evocaban en Arancibia (2005) una referencia al libro De solo estar (1957)

\footnotetext{
8 Como dice Oubiña (2009, p. 16), La ciénaga "se recorta sobre el territorio caduco de las economías regionales tradicionales. Es un mundo asfixiado y sin salida en el que nada nuevo puede producirse".

9 Para un análisis antropológico e histórico de estas dimensiones, véase Álvarez Leguizamón (2010).

${ }^{10}$ Moscoso se inspiró en HyR Maluf, una importante tienda de electrodomésticos del NOA que ya no existe. El hecho de que la familia Badur sea de ascendencia sirio-libanesa, aunque aparece integrado de manera natural en la película, es una forma inteligente de incluir a una importante comunidad migratoria con una historia de cien años en Salta que raramente aparece representada en las producciones audiovisuales. De cierta manera, la película señala que la sociedad salteña no está conformada solamente por criollos e indígenas.

${ }^{11}$ En una entrevista, de Diego Brodersena Moscoso, se habla de los clásicos It Happened One Night (Frank Capra, 1934) y Bringing Up Baby (Howard Hawks, 1938), y de la relectura del género llevada a cabo por What's Up, Doc? (Peter Bogdanovich, 1972), como posibles influencias. La screwball comedy también tuvo un desarrollo destacado en el cine argentino clásico, al cual aludiré más adelante en el texto.
} 
del poeta salteño Manuel J. Castilla. Para el crítico, la imagen de solo estar de gran pregnancia en Salta funciona "muchas veces como una manera de justificar la pasividad provinciana que la diferencia de las urgencias de la metrópoli porteña", disposición que a su vez "se transforma en un rasgo conservador que lo único que permite es la contemplación y no la acción concreta" (2005, p. 38). Me interesa retomar estas ideas, porque en Badur Hogar aparece una variación contemporánea de esto, encarnada en el protagonista. Su madre y su novia lo definen tiernamente como "un poco quedado" y Martín Galarza (antiguo compañero de secundaria, pedante, adinerado y exiliado en Buenos Aires) se aprovecha de esa descripción para para opinar sobre el ethos salteño: "Salta es así. Salta te pone así, por eso yo no volvería. Acá son todos unos quedados [...] La gente es chata acá [...] En las ciudades grandes es distinto. Acá Salta es... es la chatura misma Salta [...] Los salteños son así”. Pero la existencia ociosa, inconstante e inmadura de un personaje que ya tiene 35 y está desempleado, en el universo salteño de Badur Hogar, paradójicamente, no se traduce en inmovilidad ni en contemplación pasiva. Por el contrario, es la condición de posibilidad para que, en su desorientación, Juan conozca a Luciana y la narración se motorice en una serie de enredos amorosos. Ciertamente, entre ambos hay una diferencia ineludible: él es de Salta y ella es de Buenos Aires. Sin duda, el letargo salteño del personaje masculino se ve alterado por el atolondramiento porteño del personaje femenino. Pero esto no solo responde al modo de ser de alguien criado en una ciudad del interior, frente a la forma de vida de quien fue educado por la vorágine de una metrópolis; sino, nuevamente, se debe a que Badur Hogar es fiel a un género cinematográfico que desde su consolidación en los años 30 tiene por protagonista a una mujer independiente, impredecible y mucho más perspicaz que el hombre. Por otra parte, si bien ella es porteña y en principio su estadía en Salta es temporal, a diferencia de Galarza -el salteño desarraigado- nunca presenta a Buenos Aires como un modo de vida superior, y solo amenaza con volverse cuando la relación entra en crisis por las mentiras de Juan.

Se podría decir, entonces, que aquel supuesto rasgo definitorio y limitante de la salteñidad encuentra en la comedia romántica un encause ideal e, incluso, invierte su sentido, ya que el tiempo ocioso es fundamental para el desarrollo y el autoconocimiento de la pareja en un género que celebra que sus protagonistas disfruten de perder el tiempo juntos. Aunque, como dice Cavell (1981) en su estudio fundacional sobre la screwball comedy, "cuando están juntos no tienen tiempo que perder" (p. 96). Lejos de la parsimonia provinciana, Juan y Luciana están en constante movimiento por la ciudad $^{12}$, tal como sucedía con los veinteañeros de Modelo 73 que, pese a cierta abulia adolescente, no paraban de verse envueltos en nuevas situaciones. Pero no es que los treintañeros de Badur Hogar estén viviendo una adolescencia extendida, sino más bien que su comportamiento se vincula al universo lúdico de la niñez. Es decir, otro rasgo característico de la comedia romántica, la cual se resiste a la solemnidad de la adultez y crea un marco propicio para que los integrantes de la pareja puedan volver a ser niños

\footnotetext{
${ }^{12}$ Sin recurrir en figuraciones turísticas, la película atraviesa una cantidad enorme de paisajes urbanos y alrededores de Salta: el mercado de San Miguel, el barrio Ciudad del Milagro, el Paseo Güemes, los barrios privados, el castillo de San Lorenzo, el Cerro San Bernardo, La caldera, entre otros.
} 
mediante "la espontaneidad, la improvisación y el intercambio de roles" (Glitre, 2006, p. 56).

Por esta misma razón, es extraño encontrar niños en la screwball comedy clásica - Badur Hogar también se ajusta a ello- y la maternidad nunca es un problema o un tema relevante (a diferencia de lo que sucede en el melodrama). Los hijos no están en el horizonte, porque es la pareja misma la que se comporta aniñadamente, priorizando el juego sobre los mandatos sociales. De hecho, Juan y Luciana, lo primero que hacen al conocerse es jugar: simulan estar casados para engañar a Galarza y su esposa, y sostienen ese cambio de roles a lo largo de toda la película. Juegan, también, en la tienda abandonada de la familia Badur, que en un primer momento funciona como un refugio para Juan, atrapado en un pasado nostálgico del que no puede salir (el plano inicial de la película [figura 2] consiste en él acostado en una cama del negocio mientras recibe un llamado de su madre). Pero, cuando Luciana irrumpe en su vida, se resignifica en un espacio lúdico y erótico donde además de tener relaciones sexuales (hay toda una secuencia de montaje dedicada a esto) se divierten con los viejos electrodomésticos como si fueran niños.

Esta infantilización, en lugar de ser un rasgo negativo, es uno de los mecanismos claves que tiene la comedia romántica para llevar a cabo su objetivo de reinventar las condiciones de la unión amorosa. A diferencia de otros modelos de matrimonio que nos presenta la película (Galarza y Paola, los padres de Juan, Luciana y su ex), la pareja protagonista se sustenta en el compañerismo y en la diversión mutua. Así, después de estar juntos y perder el tiempo juntos, y gracias al juego y el simulacro (que no casualmente se inician en una fiesta de casamiento), la relación entre Juan y Luciana culmina en una suerte de nuevo matrimonio. El plano final (figura 3) consiste en la pareja con una cama matrimonial de fondo, el único objeto que pervivió del negocio familiar y con el que ella tenía una fascinación particular.

Figura 2: Juan, en el primer plano de la película, amanece en el negocio de su padre y con el llamado de su madre.

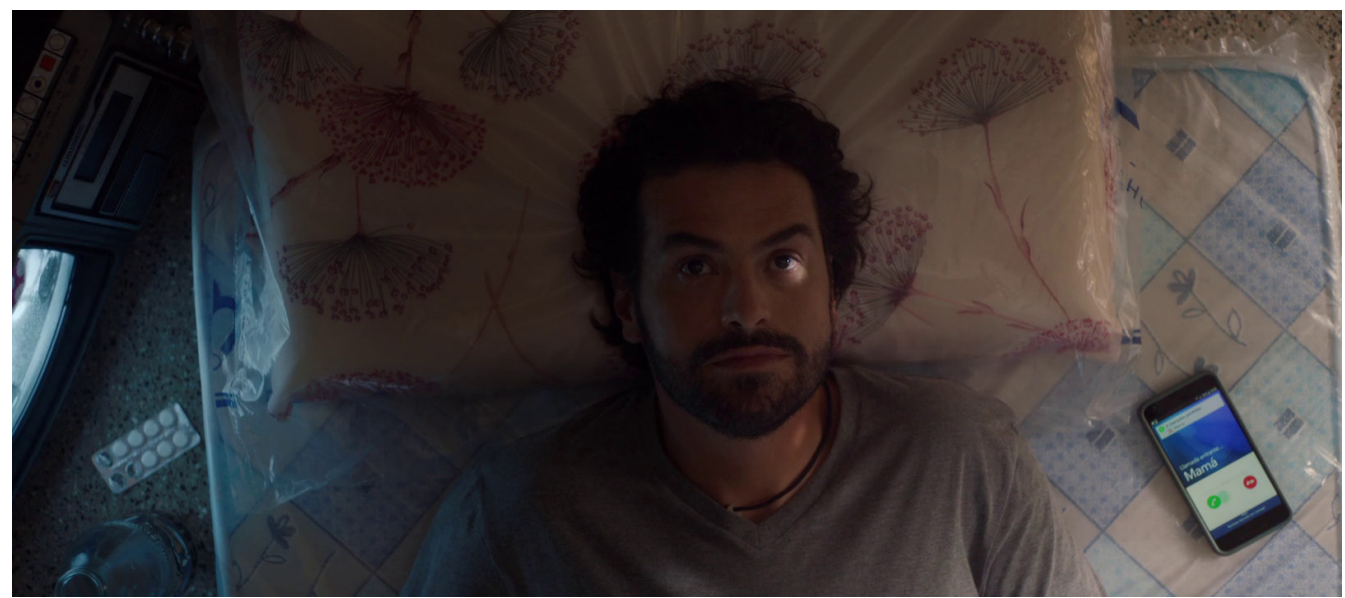


Figura 3: Juan y Luciana en el plano final de la película se reconcilian con la cama matrimonial de fondo.

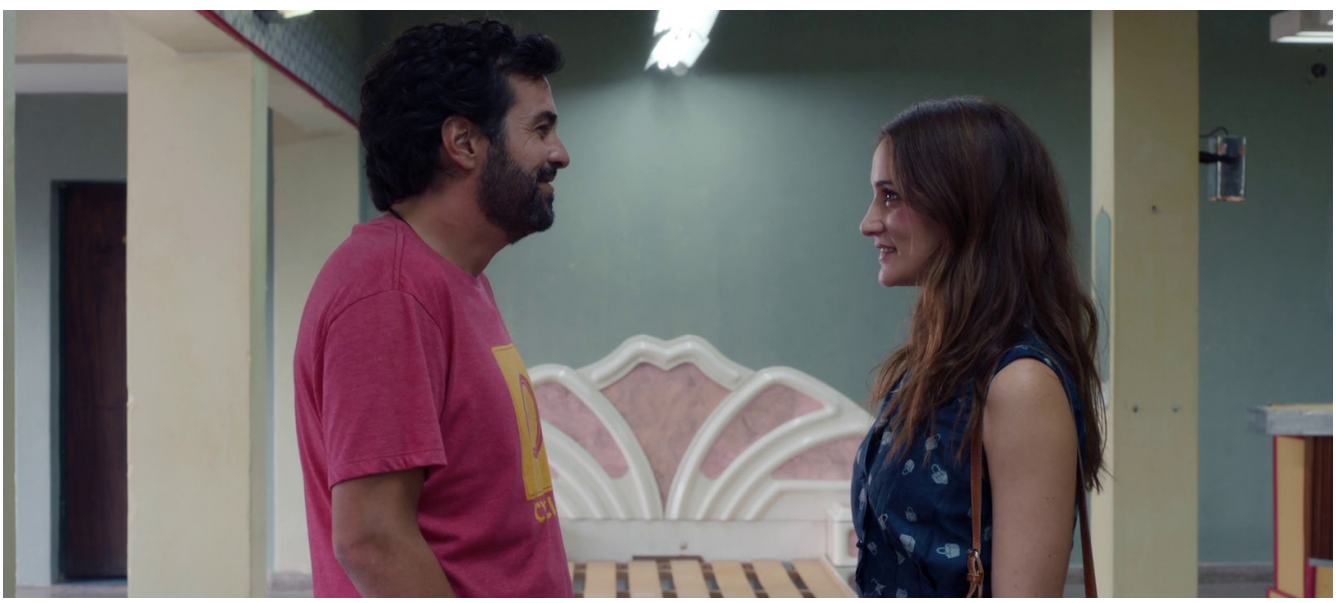

La aparición de la porteña Luciana es capaz de reorientar la quedadez provinciana de Juan hacia una dinámica lúdica y erótica y, a su vez, lo incentiva a tomar una decisión respecto de Badur Hogar sacándolo de su parálisis. Como contrapartida, ella no vuelve a Buenos Aires como tenía planeado y se integra a la sociedad salteña. Este movimiento pone en serie a la película de Moscoso con la primera screwball comedy argentina ${ }^{13}: L a$ rubia del camino (Manuel Romero, 1938), donde una chica moderna, alocada y porteña renunciaba a Buenos Aires y se retiraba al interior del país con su nuevo amor. Es cierto que, en aquella temprana adaptación nacional de un género de Hollywood, Romero recurría a la comedia romántica para poner en el centro de la historia la ferviente oposición entre pobres y ricos, latente en la sociedad argentina de los años 30 (Karush, 2013). Un conflicto que en la película de Moscoso no está en primer plano, sin embargo, esto no implica que no exista. ¿Qué puede decir, entonces, esta comedia romántica de la sociedad salteña?

Cuando Cavell (1981) sostiene que la screwball comedy "necesita que la pareja disponga del tiempo necesario para estar juntos, para perderlo juntos" (p. 96), no solo habla de cierta disposición de la pareja hacia el juego y el ocio, sino de un contexto socio-económico determinado. Este género requiere un "marco lujoso", "un entorno snob" o, como mínimo, "personajes centrales cuyo trabajo pueda posponerse sin que teman perderlo, o sea precisamente seguir los acontecimientos hasta su conclusión (en vez de la rutina diaria de nueve a cinco)" (p. 96). En este sentido, que en Badur Hogar no aparezcan las familias terratenientes en sus estancias con las diversas y habituales formas de abuso de los patrones hacia los peones -tal como sucede en otras producciones del NOA- ni se manifieste una crítica social explícita, no quiere decir

${ }^{13}$ Véase Kelly Hopfenblatt (2019). Badur Hogar recupera una tradición genérica que el cine argentino después de su período clásico (1930-1960) dejó de lado, priorizando comedias costumbristas o picarescas. En las dos últimas décadas hubo un renacimiento de la comedia romántica a nivel local pero curiosamente sus protagonistas femeninas son menos independientes y punzantes que las heroínas de los años 30 y 40. 
que se desentienda de la cuestión de clase. Un aspecto que, como ha profundizado Beach (2002), fue crucial en la comedia romántica desde los comienzos del sonoro, dada su capacidad para representar las tensiones sociales y transgredir las identidades establecidas volviéndolas risibles.

En la película de Moscoso, aquella clase alta tradicional salteña toma la forma de los nuevos ricos que viven en los barrios privados de la ciudad y que se relacionan con sus empleados a través de una lógica similar (así lo experimentan los pileteros al intentar sin éxito cobrar un trabajo ya realizado). Martín Galarza es uno de los representantes de este grupo social, y se distingue de las viejas elites en que no siente ningún tipo de arraigo hacia Salta, desprecia la vida de provincia, prefiere vivir en Buenos Aires y trabaja como asesor financiero de una multinacional de agroquímicos. No obstante, como se devela al final, lo cierto es que lo echaron del trabajo y está tapado de deudas. Aparece, también, la burguesía comercial representada en la familia Badur, de donde proviene el protagonista, que no siguió la tradición familiar de vivir para el trabajo. Sin embargo, cierta vagancia y errancia, lo predisponen para cruzar la burbuja de su clase social y conocer a Gaspar con quien limpia piletas. Este es el único personaje de extracción popular y el único que verdaderamente trabaja en un universo donde el rico resulta ser un fraude, el viejo empresario Badur está retirado y arrepentido de no haber seguido otro camino en su vida, y Juan es inmaduro y "quedado".

Gaspar es, además, el único que le habla sin filtro. Con rasgos indoamericanos pero metalero, en otra inversión de las representaciones típicas de los sectores populares del NOA, le dice a Juan: "no seas pajero, si vos no necesitás la plata porque naciste en una cuna de oro, yo sí la necesito"; "avísame cuando sea mi turno de sentirme mal así vos hacés la experiencia de laburar"; "qué te hacés el pobre si lo pagaste con la tarjeta de tu viejo". Con todo, y si bien Badur Hogar presenta un final optimista fiel a la imaginación utópica de las comedias donde las diferencias de clase se liman (Galarza confiesa la verdad de su situación económica y se disculpa; Juan le financia el emprendimiento a Gaspar para que continúe en soledad), la película nunca peca de ingenua. Tal vez el plano más elocuente, en este sentido, sea aquel en el que Moscoso apela a un recurso visual particular (muy usado en la comedia física) para mostrar desde el comienzo del relato la estructura social que está en su base. Como se ve en la figura 6, mediante la utilización de la profundidad de campo, la imagen despliega tres capas: en el frente del cuadro, los dos personajes de familias acomodadas conversando en el interior del hogar; en el medio, la esposa de Martín tomando Sol en el jardín (con quien Juan, además, tuvo una relación amorosa en su juventud) y, en el fondo, Gaspar trabajando en la pileta. 
Figura 4: El volante que diseña Gaspar tiene cruces invertidas, nada más alejado de la pregnante religiosidad cristiana salteña.

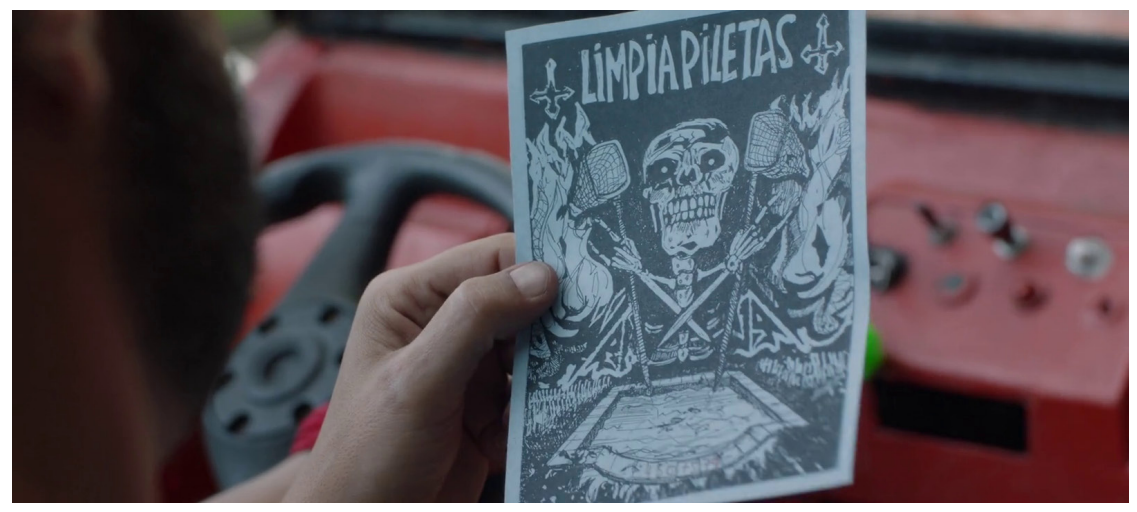

Figura 5: Los patrones posponen el pago a los pileteros.

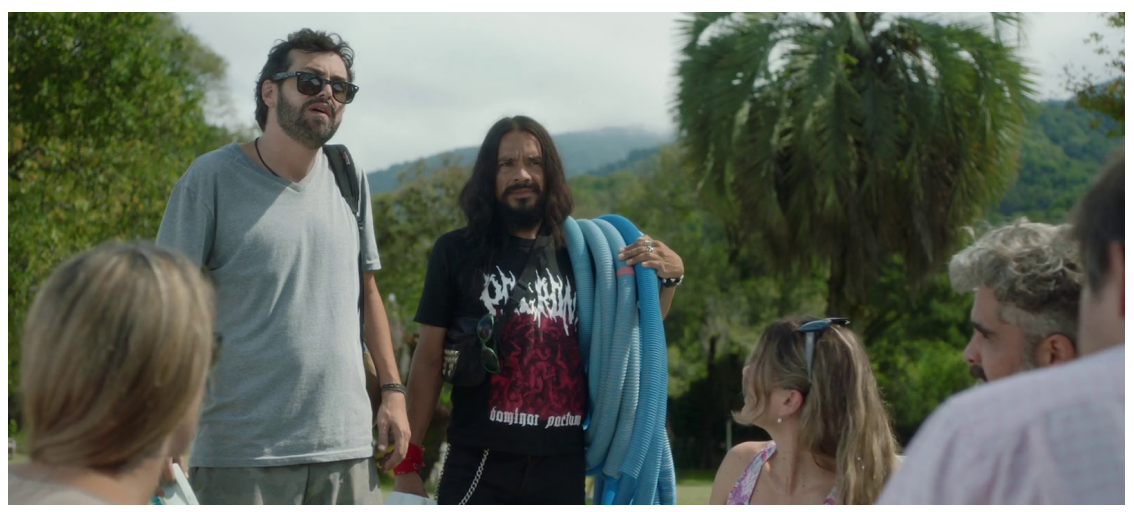

Figura 6: La representación visual de la estructura social de Badur Hogar.

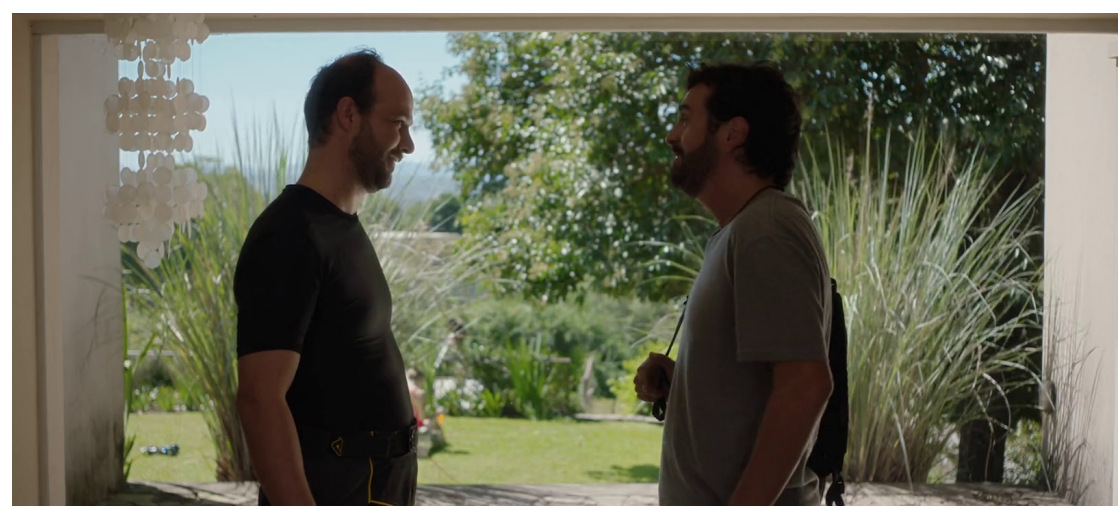




\section{Epílogo}

"Yo admiro mucho a Lucrecia Martel, le admiro la paciencia que tiene, el hecho de decir 'no filmo hasta que no tengo todo cerrado'. Ya tiene arreglada la distribución, lo filmó con inversiones privadas. A mi me gustaría ser más así. La próxima, voy a tratar de hacer una película de manera más ordenada. Es como una limitación que tengo en ese sentido" (Schwarzböck, 2000, p. 47). Casi dos décadas más tarde, Moscoso cumplió esa promesa tímida que había lanzado a comienzos de su carrera (cuando Martel, que para entonces solo había estrenado su corto Rey Muerto, ya era una referencia ineludible) y de cierta manera volvió a filmar Modelo 73, una historia de amor durante un verano salteño con personajes ociosos y deambuladores. Pero ya no bajo las condiciones económicas y estéticas del cine independiente, sino en el marco de una estructura de producción más industrial y ateniéndose a la narrativa genérica de la comedia romántica clásica; tampoco, bajo el signo de Martel.

De manera similar a lo que hizo la salteña Barbara Sarasola-Day con su segunda película -el thriller Sangre Blanca (2018)-, Moscoso con Badur Hogar demuestra que es posible para los cines regionales apostar al cine de género y contar historias producidas ${ }^{14} \mathrm{y}$ situadas en las provincias que hablen universalmente. En este caso, la comedia romántica le permite escapar a la imagen pintoresca de Salta, tan arraigada en el imaginario nacional, y narrar un romance urbano que combina cuestiones específicas de la salteñidad y de una capital de provincia con elementos propios de un género transnacional.

Figura 7: El nombre de la Pinturería Martel (perteneciente al padre de Lucrecia) se infiltraba en Modelo 73.

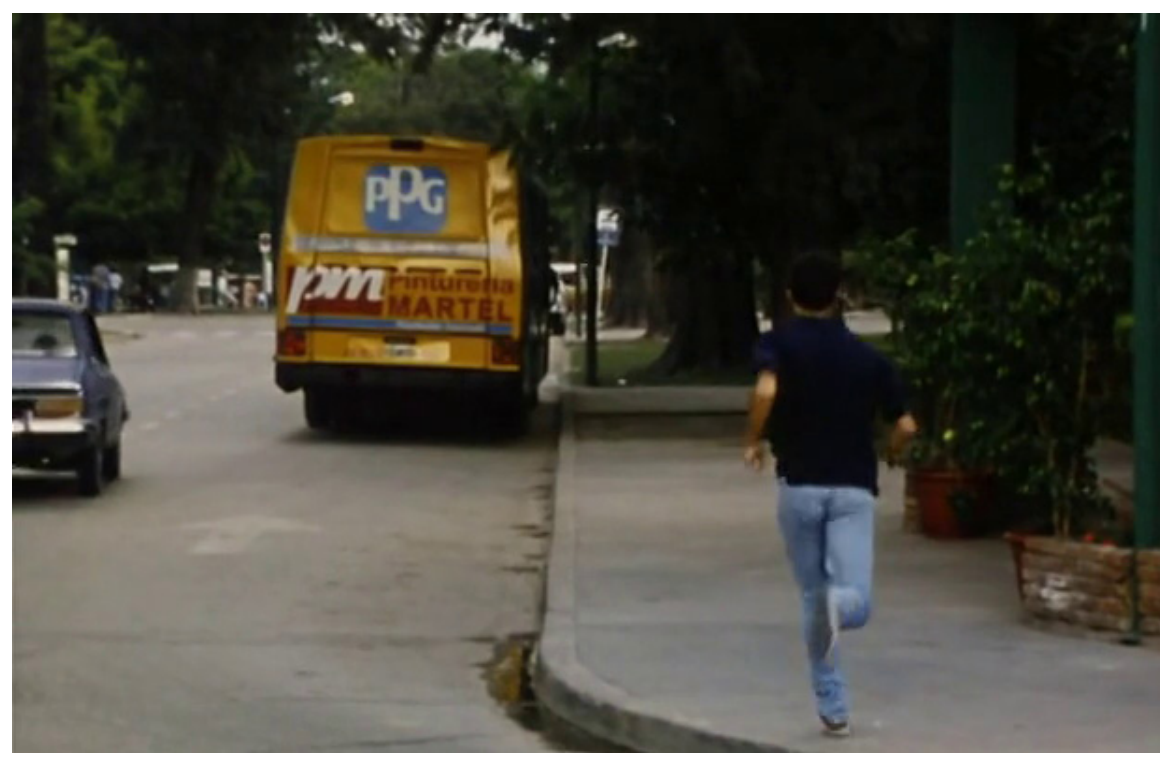

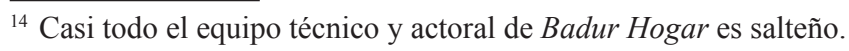




\section{Referencias bibliográficas}

Aguilar, G. (2009). Episodios cosmopolitas en la cultura argentina. Buenos Aires: Santiago Arcos.

Álvarez Leguizamón, S. (Comp.). (2010). Poder y salteñidad. Saberes, politicas y representaciones sociales. Salta: CEPIHA.

Anderman, J. (2015). Nuevo cine argentino. Buenos Aires: Paidós.

Arancibia, V. (2005). "Lugares, miradas e identidades. La construcción de representaciones en el cine de Lucrecia Martel". En A. Cebrelli y V. Arancibia (Comps.), Representaciones sociales. Modos de mirar y de hacer (pp. 33-49). Salta: CIUNSa.

Arancibia, V. (2015). Nación y puja distributiva en el campo audiovisual. Identidades, memorias y representaciones sociales en la producción cinematográfica y televisiva del NOA (2003-2013). Universidad Nacional de La Plata. (Tesis doctoral).

Arancibia, V. y Barrios, C. (2018). “Introducción. Disputas culturales: producción audiovisual y configuración de las regiones en Argentina". Folia Histórica del Nordeste, 31, 27-36.

Arancibia, V. y Saavedra, M. N. (2018). "La construcción de las imágenes de Salta. Articulaciones entre noticias y ficciones cinematográficas". En: Revista Folia Histórca del Nordeste, $\mathrm{N}^{\mathrm{o}} 31$, pp. 98-119.

Beach, C. (2002). Class, Language, and American Film Comedy. Cambridge: Cambridge University Press.

Brodersen, D. (2019, mayo 12). "Cine salteado". Página/12. https://www.pagina12. com.ar/192906-cine-salteado.

Cavell, S. ([1981] 1999). La búsqueda de la felicidad. La comedia de enredo matrimonial en Hollywood. Barcelona: Paidós.

Devoto, F. (2002). Nacionalismo, fascismo y tradicionalismo en la Argentina moderna. Una historia. Buenos Aires: Siglo XXI.

Fasce, P. (2017). El noroeste y la institucionalización de las artes en Argentina: tránsitos, diálogos y tensiones entre región y nación (1910-1955). Universidad Nacional de San Martín. Tesis doctoral.

Glitre, K. (2006). Hollywood Romantic Comedy: States of the Union, 1934-1965. Manchester: Manchester University Press.

Karush, M. (2013). Cultura de clase. Radio y cine en la creación de una Argentina dividida (1920-1946). Buenos Aires: Ariel.

Kelly Hopfenblatt, A. (2019). Modernidad y teléfonos blancos. La comedia burguesa en el cine argentino de los años 40. Buenos Aires: Ciccus.

Oubiña, D. (2009) Estudio crítico sobre La ciénaga. Buenos Aires: Picnic editorial.

Schwarzböck, S. (2000, octubre). "Modelo para armar". El Amante, 103, 42-47. 